\section{Beware of Temperature Changes: A Case Report of Paroxysmal Cold Haemoglobinuria}

Mafalda Matias ${ }^{1 *}$, Catarina Lacerda ${ }^{1}$, Inês Ganhão1, Maria São Pedro $^{1}$, Maria João Palaré ${ }^{2}$, Isabel Leal ${ }^{3}$ and Susana Correia ${ }^{1}$

${ }^{1}$ Department of Pediatrics, Centro Hospitalar Barreiro-Montijo, Barreiro, Portugal

${ }^{2}$ Department of Pediatrics Hematology, Hospital de Santa Maria, Lisboa, Portugal

${ }^{3}$ Department of Immunohemotherapy, Centro Hospitalar Barreiro-Montijo, Barreiro, Portugal bin <8 mg/dL; LDH $1328 \mathrm{UI} / \mathrm{L}$; bilirubin $1 \mathrm{mg} / \mathrm{dL}$ and unconjugated bilirubin $0.6 \mathrm{mg} / \mathrm{dL}$ ), C-reactive-protein $56.7 \mathrm{mg} / \mathrm{L}$. He received a transfusion of red blood cells, initiated treatment with oral clarithromycin and reinforced the rewarming of the extremities with good results $(\mathrm{Hb} 9.6 \mathrm{~g} / \mathrm{dL}$ ). Regarding serological investigation, the results revealed a positive IgM for Mycoplasma pneumoniae; positive Direct Antiglobulin Test with specificity for CD3, and positive Donath Landsteiner test, leading to the diagnosis.

This case report represents a syndrome that even though rare, is important to bear in mind when facing a case of severe haemolysis Despite the favorable outcome, additional follow-up must be placed in outpatient setting, with periodic clinical and laboratorial revaluations.

Keywords: Cold; Donath landsteiner; Haemoglobinuria; Mycoplasma pneumonia

\author{
Abbreviations \\ CMV: Cytomegalovirus \\ CRP: C-Reactive Protein \\ C3d: Complement 3d \\ DCT: Direct Coombs Test \\ EBV: Epstein-Barr Virus \\ $\mathrm{Hb}$ : Hemoglobin \\ Htc: Hematocrit \\ ICT: Indirect Coombs Test \\ IgG: Immunoglobulin G \\ IgM: Immunoglobulin M \\ LDH: Lactate Dehydrogenase \\ L: Lymphocytes \\ MGV: Mean Globular Volume \\ $\mathrm{N}$ : Neutrophils \\ PCH: Paroxysmal Cold Haemoglobinuria \\ RBC: Red Blood Cells
}

\section{Introduction}

Paroxysmal Cold Haemoglobinuria (PCH) is a rare form of autoimmune haemolytic anaemia. It is characterized by the presence of IgG autoantibodies that bind to the P antigen on the Red Blood Cell (RBC) surface [1-5] sensitizing the RBCs by fixing complement. This occurs in the extremities at colder temperatures [5], and upon circulation on warmer parts of the body, there is activation of the complement cascade resulting in intravascular haemolysis and haemoglobinuria $[1,4,5]$.

Despite being a disease that might appear at any age, it is more common among the paediatric age group $[1,4,6]$. Most cases are seen in children under 5 years of age, with male predominance [5]. According to European epidemiologic studies, even though populational data are limited, its estimated prevalence varies between $1.6 \%$ and 40 $\%$ of all autoimmune haemolytic anaemia episodes $[4,5]$. The recent raise in its incidence could be due to an increase in the awareness of the disease and of the Donath-Landsteiner Test [3].

Copyright: (C) 2019 Matias M, et al. This is an open-access article distrib under the terms of the Creative Commons Attribution License, which permits unrestricted use, distribution, and reproduction in any medium, provided the origina author and source are credited. 
This syndrome usually appears within 7-10 days after an infection and may persist for 6-12 weeks after its resolution [1]. Severe anemia, pallor, haemoglobinuria, presence of intravascular haemolysis, without hepatosplenomegaly are typical manifestations of this syndrome [1-6]. Usually there is a significant improvement just with supportive measures, $\mathrm{RBC}$ transfusion and antibiotics when there is a bacterial underlying infection, with no need to use corticosteroids or immunosuppressive drugs, as seen in the case presented.

\section{Case Report}

A twenty-one months old caucasian male child was admitted with a 6-day-history of fever (maximum temperature of $40^{\circ} \mathrm{C}$, with $3-4$ peeks per day, unresponsive to antipyretics), malaise, productive cough, vomiting and diarrhea. He had no relevant family or personal history, with no known anaemias; and no recent consumption of favas beans or any type of drugs. He was medicated with amoxicillin and clavulanic acid two days before for an upper respiratory infection (acute tonsillitis).

On physical examination, the child was prostrated, hemodynamically stable (arterial pressure: 97/53 mmHg; cardiac frequency: 128 $\mathrm{bpm}$, capillary reperfusion time $<2 \mathrm{~s}$ ) and without respiratory distress signs. He was severely pale, hydrated but without jaundice. He also had bilateral tympanic membrane hyperaemia and tonsillar hypertrophy with purulent exudate. There were no further changes in the physical examination, namely: No palpable organomegaly, lymphadenopathies or macroscopic changes in urine. Blood tests revealed the presence of severe microcytic and hypochromic anaemia $(\mathrm{Hb} 5.4$ $\mathrm{g} / \mathrm{dL}$, Htc $15.9 \%$, MGV $82 \mathrm{fL})$, leucocytosis (19.90 x 10/L with $44.7 \% \mathrm{~N} ; 44.6 \% \mathrm{~L}$ ), without immature or abnormal red cells in the peripheral blood smear and a C-Reactive Protein (CRP) $56.7 \mathrm{mg} / \mathrm{L}$. There was evidence of haemolysis (reticulocytosis $89.7 \times 10^{6} / \mathrm{L}$, haptoglobin $<8 \mathrm{mg} / \mathrm{dL}$ (30-200 mg/dl), Lactate Dehydrogenase (LDH) $1328 \mathrm{UI} / \mathrm{L}$; bilirubin $1 \mathrm{mg} / \mathrm{dL}$ and unconjugated bilirubin $0.6 \mathrm{mg} / \mathrm{dL}$ ).

After consulting the immunohemotherapy and paediatric haematology departments, other complementary exams were requested. The Direct Antiglobulin Test (Direct Coombs Test) was positive for Complement Component 3d (C3d) and the Indirect Antiglobulin Test (Indirect Coombs Test); was negative. The serologic tests revealed positive Immunoglobulin $\mathrm{G}$ (IgG) for Cytomegalovirus (CMV) and Epstein-Bar Virus (EBV) and positive Immunoglobulin M (IgM) for Mycoplasma pneumoniae. The final diagnosis of $\mathrm{PCH}$ was established by the previous results and a positive Donath-Landsteiner Test.

Upon admission, he received a transfusion of red blood cells (15 $\mathrm{mL} / \mathrm{Kg}$ ), with a good response-a rise in the haemoglobin level to $9 \mathrm{~g} /$ $\mathrm{dL}$ (post transfusion) and $9.9 \mathrm{~g} / \mathrm{dL}$ at discharge (D6). Treatment with oral clarithromycin was initiated and some supportive measures were reinforced, such as rehydration, extremities rewarming and prevention of cold exposure. While admitted, he experienced progressive clinical and analytical improvement, with haemolysis resolution (reticulocytes $253 \times 10^{6} / \mathrm{L}$; bilirubin $0.40 \mathrm{mg} / \mathrm{dL}$; unconjugated bilirubin $0.20 \mathrm{mg} / \mathrm{dL}$; LDH $923 \mathrm{UI} / \mathrm{L}$ and haptoglobin $12 \mathrm{mg} / \mathrm{dL}$ ).

After discharge, a follow-up appointment by a paediatric haematologist was made. At 2 months follow-up, the child remained without any recurrence of the symptoms, with haemoglobin levels of $12 \mathrm{~g} /$ $\mathrm{dl}$, without reticulocytosis or any other evidence of haemolysis. The initial immunohematological tests were repeated, confirming the previously established diagnosis.

\section{Conclusion}

Faced with a case of a previously healthy child who develops severe acute anaemia accompanied by reticulocytosis, a haemolytic pattern and a normal peripheral blood smear, an autoimmune cause must be considered and a Coombs Test should be requested. Our patient's Direct Coombs Test showed monospecificity for C $3 \mathrm{~d}$ which is very suggestive of a cold agglutinin-mediated autoimmune haemolytic anemia.

The final diagnosis was possible through the Direct Coombs Test, that was positive to anti-C3 and negative to $\operatorname{IgG}[1,3-6]$; and a positive Donath-Landsteiner Test, with addition of complement. This test revealed the acquired haemolytic anemia caused by biphasic IgG autoantibodies that sensitize RBCs at cold temperatures by fixing complement to the RBCs causing intravascular haemolysis upon rewarming $[3,6]$. This allowed the differential diagnosis with other diseases, such as Paroxysmal Nocturnal Haemoglobinuria and Cold Agglutinin Disease, that despite being clinically and analytically similar, have a different pathophysiology [3-5].

Nowadays, the PCH is more associated with viral infections and post-immunization status [1,4-6]. The most frequently associated agents are the measles, mumps, influenza, herpes, varicella, CMV, EBV, adenovirus, parvovirus B19, Coxsakie A9, Haemophilus influenzae, Mycoplasma pneumoniae and Klebsiella pneumoniae [4,5]. Other potential causes, although less frequent, are lymphoproliferative and other auto-immune diseases. In this case report, the $\mathrm{PCH}$ appears concurrent to an upper respiratory infection, a positive result of the serological test for Mycoplasma pneumoniae led us to consider this as the likely cause of this haematological syndrome.

The majority of the PCH episodes are acute and with spontaneous resolution within weeks, and just requiring some supportive and preventive measures $[1,3,4]$. Cold exposure should be avoided, hydration reinforced and attention to any sudden worsening of the child's well-being $[1,4,5]$. When facing a severe and symptomatic anaemia, warmed blood transfusion might be necessary $[1,3]$, as in the case presented. Because most cases of acute PCH are transient and self-limited, there is usually no need for immunosuppressive or pharmacologic drug therapy [5]. A few studies have been performed to evaluate the role of corticosteroids in haemolysis's control, but the results were inconclusive [1,3-6]. On the other hand, the use of immunosuppressive drugs such as rituximab (an anti-CD20 monoclonal antibody) proved to be helpful in reverting haemolysis in refractory cases [5]. More recently, a new recombinant antibody-eculizumab-has also been under investigation. Theoretically, for its inhibitory effect on the complement cascade, it seemed a promising drug, yet the results were rather disappointing [5]. Regardless of its favorable prognosis and rarely recurrent, a close clinical and analytical follow-up is essential in $\mathrm{PCH}$, just has seen in the case presented.

This case report represents a syndrome that even though rare, is important to bear in mind when facing a case of severe haemolysis. It's a disease that generally has a benign course, being the knowledge of the diagnostic test and the avoidance of cold exposure the cornerstones for a fast and correct diagnosis, and determinant to recovery. Despite being self-limited and usually non-recurrent, sometimes severe presentations of this haemolytic syndrome might occur to which we should be aware. 


\section{Acknowledgement}

The authors would like to thank the assistance and collaboration of Carlos Riachos and Maria Inês Moser of the Portuguese Institute of Blood and Transplantation in the investigation and accomplishment of the most appropriate complementary exams for the clinical diagnosis.

\section{Conflict of interest}

None of the authors have any relevant conflicts of interest to report.

\section{References}

1. Carlo B (2017) Paroxysmal cold hemoglobinuria. UpToDate, Massachusetts, USA.
2. Matos C, Teixeira S, Lira S, Costa E, Barbot J (2012) Hemoglobinúria paroxistica aofrio: Quando suspeitar? Nascer e Crescer 21: 135-137.

3. Shanbhag S, Spivak J (2015) Paroxysmal cold hemoglobinuria. Hematol Oncol Clin North Am 29: 473-478.

4. Fadeyi EA (2014) Paroxysmal cold hemoglobinuria: Not an "uncommon" disease anymore. J Hematolo Thrombo Dis 2: 162.

5. Slemp SN, Davisson SM, Slayten J, Cipkala DA, Waxman DA (2014) Two case studies and a review of paroxysmal cold hemoglobinuria. Lab Med 45: 253-258.

6. Radhakrishnan N, Sacher RA (2018) Paroxysmal cold hemoglobinuria. Medscape, New York, USA. 


\section{di \\ HERALD}

Journal of Anesthesia \& Clinical Care

Journal of Addiction \& Addictive Disorders

Advances in Microbiology Research

Advances in Industrial Biotechnology

Journal of Agronomy \& Agricultural Science

Journal of AIDS Clinical Research \& STDs

Journal of Alcoholism, Drug Abuse \& Substance Dependence

Journal of Allergy Disorders \& Therapy

Journal of Alternative, Complementary \& Integrative Medicine

Journal of Alzheimer's \& Neurodegenerative Diseases

Journal of Angiology \& Vascular Surgery

Journal of Animal Research \& Veterinary Science

Archives of Zoological Studies

Archives of Urology

Journal of Atmospheric \& Earth-Sciences

Journal of Aquaculture \& Fisheries

Journal of Biotech Research \& Biochemistry

Journal of Brain \& Neuroscience Research

Journal of Cancer Biology \& Treatment

Journal of Cardiology: Study \& Research

Journal of Cell Biology \& Cell Metabolism

Journal of Clinical Dermatology \& Therapy

Journal of Clinical Immunology \& Immunotherapy

Journal of Clinical Studies \& Medical Case Reports

Journal of Community Medicine \& Public Health Care

Current Trends: Medical \& Biological Engineering

Journal of Cytology \& Tissue Biology

Journal of Dentistry: Oral Health \& Cosmesis

Journal of Diabetes \& Metabolic Disorders

Journal of Dairy Research \& Technology

Journal of Emergency Medicine Trauma \& Surgical Care

Journal of Environmental Science: Current Research

Journal of Food Science \& Nutrition

Journal of Forensic, Legal \& Investigative Sciences

Journal of Gastroenterology \& Hepatology Research

Journal of Gerontology \& Geriatric Medicine

Journal of Genetics \& Genomic Sciences

Journal of Hematology, Blood Transfusion \& Disorders

Journal of Human Endocrinology

Journal of Hospice \& Palliative Medical Care

Journal of Internal Medicine \& Primary Healthcare

Journal of Infectious \& Non Infectious Diseases

Journal of Light \& Laser: Current Trends

Journal of Modern Chemical Sciences

Journal of Medicine: Study \& Research

Journal of Nanotechnology: Nanomedicine \& Nanobiotechnology

Journal of Neonatology \& Clinical Pediatrics

Journal of Nephrology \& Renal Therapy

Journal of Non Invasive Vascular Investigation

Journal of Nuclear Medicine, Radiology \& Radiation Therapy

Journal of Obesity \& Weight Loss

Journal of Orthopedic Research \& Physiotherapy

Journal of Otolaryngology, Head \& Neck Surgery

Journal of Protein Research \& Bioinformatics

Journal of Pathology Clinical \& Medical Research

Journal of Pharmacology, Pharmaceutics \& Pharmacovigilance

Journal of Physical Medicine, Rehabilitation \& Disabilities

Journal of Plant Science: Current Research

Journal of Psychiatry, Depression \& Anxiety

Journal of Pulmonary Medicine \& Respiratory Research

Journal of Practical \& Professional Nursing

Journal of Reproductive Medicine, Gynaecology \& Obstetrics

Journal of Stem Cells Research, Development \& Therapy

Journal of Surgery: Current Trends \& Innovations

Journal of Toxicology: Current Research

Journal of Translational Science and Research

Trends in Anatomy \& Physiology

Journal of Vaccines Research \& Vaccination

Journal of Virology \& Antivirals

Archives of Surgery and Surgical Education

Sports Medicine and Injury Care Journal

International Journal of Case Reports and Therapeutic Studies

Submit Your Manuscript: http://www.heraldopenaccess.us/Online-Submission.php 